\title{
Bentuk Kosakata Bahasa Inggris pada Media Sosial Lembaga Pemerintah Indonesia
}

\author{
Adinda Prasty Ascalonicawati ${ }^{1}$, Hayatul Cholsy ${ }^{2}$ \\ ${ }^{1}$ Linguistics Postgraduate Student, Faculty of Cultural Sciences, \\ Universitas Gadjah Mada, Yogyakarta, Indonesia \\ ${ }^{2}$ Language and Literature Department, Faculty of Cultural Sciences, \\ Universitas Gadjah Mada, Yogyakarta, Indonesia
}

\section{Article Info \\ Article history: \\ Submitted Jan 26, 2020 \\ Revised Feb 20, 2020 \\ Accepted April 29, 2020 \\ Published April 30, 2020 \\ Keywords: \\ English vocabulary \\ Interference \\ Language contact \\ Lexical borrowing \\ Loanword}

\section{Kata Kunci:}

Interferensi

Kata pinjaman

Kata serapan

Kontak bahasa

Kosakata Bahasa Inggris

\begin{abstract}
Many exposure of foreign languages, in this case is English, in daily communication could give significant impact towards oral and written language to the Indonesian speech community. That phenomenon was the result of language contact which is widespread in this digital era. This research aimed to identify English vocabulary which found in the caption on social media Instagram account of Ministry and NonMinisterial Government Agencies in Indonesia. Data in this research were the English loanwords vocabulary and interference which are obtained by applying observation method with screenshot and note taking technique. Data source used is the social media Instagram account of Ministry and Non-Ministerial Government Agencies in Indonesia, such as @bekrafid, @kemdikbud.ri, @ristekdikti, @kemlu.ri, @kemenpar, @infobmkg, and @kemenhub151. The results found of this study were loanwords, loanblends, and loanshifts, also phonological, morphological, and lexical interference.
\end{abstract}

\begin{abstract}
ABSTRAK
Banyaknya paparan bahasa asing, dalam hal ini bahasa Inggris, pada komunikasi sehari-hari memberikan pengaruh yang signifikan terhadap penggunaan bahasa lisan dan tulis oleh masyarakat tutur bahasa Indonesia. Peristiwa tersebut merupakan akibat dari adanya kontak bahasa yang marak dijumpai di era digital saat ini. Penelitian ini bertujuan untuk mengidentifikasi kosakata bahasa Inggris yang ditemukan dalam takarir pada media sosial Instagram Kementerian dan Lembaga Pemerintah Non Kementerian di Indonesia. Data dalam penelitian ini merupakan bentuk kosakata pinjaman dan interferensi bahasa Inggris yang diperoleh dengan menerapkan metode pengamatan dengan teknik tangkap layar dan catat. Sumber data yang digunakan berupa akun media sosial Instagram Kementerian dan Lembaga Pemerintah Non Kementerian di Indonesia, antara lain @bekrafid, @kemdikbud.ri, @ristekditi, @kemlu.ri, @kemenpar, @infobmkg, dan @kemenhub151. Hasil dalam penelitian ini yaitu terdapat kata pinjaman berupa bentuk loanwords, loanblends, dan loanshifts, serta interferensi dalam tataran fonologis, morfologis, dan leksikal.
\end{abstract}

\section{Corresponding Author:}

Adinda Prasty Ascalonicawati,

Linguistics Graduate Program, Faculty of Cultural Sciences,

Universitas Gadjah Mada

Jl. Sosiohumaniora 1, Bulaksumur, Yogyakarta, Indonesia.

Email: adindaprasty@mail.ugm.ac.id 


\section{PENDAHULUAN}

Masuknya unsur bahasa satu ke bahasa lainnya makin sering dijumpai dalam kehidupan berkomunikasi sehari-hari. Thomason (2001) menyebut peristiwa itu dengan istilah 'kontak bahasa'. Kebanyakan masyarakat tutur bahasa Indonesia bahkan tidak menganggap hal tersebut sebagai kemampuan yang istimewa lagi. Peristiwa penggunaan dua bahasa atau lebih dianggap lumrah terjadi dalam lingkungan dwibahasa pada era digital saat ini. Peristiwa kontak bahasa bermula dari masuknya bangsa-bangsa lain ke Indonesia dengan membawa bahasa asing yang selanjutnya memberikan pengaruh terhadap bahasa yang digunakan sehari-hari oleh masyarakat Indonesia. Jika diperhatikan dengan saksama dari segi pendidikan, penguasaan bahasa tersebut dimulai sejak proses belajar mengajar di bangku sekolah. Pada tahap itu, tiap siswa diwajibkan untuk menggunakan bahasa Indonesia sebagai bahasa pengantar resmi pendidikan di negara ini. Hal tersebut memegang peran penting dalam penguasaan bahasa Indonesia setelah bahasa pertama masing-masing siswa yang diajarkan di rumah, yakni bahasa daerah. Selain itu, penguasaan bahasa asing pun diperoleh dari mata pelajaran yang diajarkan di sekolah, dalam hal ini tentu saja bahasa Inggris.

Selain berkomunikasi secara lisan, pengaruh bahasa asing juga dapat diamati dari bahasa tulis. Pada era digital saat ini, bahasa tulis sangat mudah ditemui dalam berbagai wadah media sosial, seperti contoh Instagram. Dengan dilengkapi fitur caption, tiap pengguna aktif internet dapat dengan mudah mengunggah foto dengan menyertakan keterangan di tiap unggahannya. Caption dalam bahasa Indonesia memiliki padanan kata yaitu 'takarir'. Namun, masih sangat jarang diketahui dan digunakan oleh para pengguna aktif internet atau yang lebih dikenal dengan istilah 'netizen' (warganet). Sebagai gambaran, berikut contoh takarir yang diunggah pada tanggal 29 Agustus pada akun media sosial Instagram Badan Ekonomi Kreatif (@bekrafid) yang mengandung kosakata bahasa Inggris di dalamnya, yaitu:

"Selamat untuk 20 peserta yang terpilih \#SCARA2019 yang lolos tahap administrasi dan wawancara. Terima kasih atas partisipasi dan antusiasme terhadap program ini. Mari bersamasama terus meningkatkan kualitas konten ramah anak untuk anak-anak Indonesia. Sampai jumpa di sesi 1 workshop inkubasi. Tanggal: 6-9 September 2019."

Contoh 1. Takarir pada akun @bekrafid

Berdasarkan contoh di atas, terdapat beberapa kosakata pinjaman dan interferensi yang tercetak tebal, antara lain administrasi, partisipasi, antusiasme, program, kualitas, konten, dan inkubasi, dan workshop. Pada beberapa contoh interferensi morfologi, terdapat perubahan sufiks '-ation' dalam bahasa Inggris menjadi '-asi' dalam kata 'administrasi', 'partisipasi', dan 'inkubasi'. Hal serupa juga berlaku dalam contoh kata 'kualitas' yang mengalami perubahan sufiks '-ity' menjadi '-itas'. Selanjutnya, terdapat perubahan ejaan dan juga pelesapan huruf akhir pada kata 'antusiasme' yang berasal dari kata 'enthusiasm' dan 'konten' yang berasal dari kata 'content'. Selain itu, terdapat kata pinjaman yang tidak mengalami perubahan secara ejaan atau penulisan (ortografis), melainkan dari segi pelafalan atau bunyi (fonologis), yaitu kata 'program'. Sebagai tambahan, terdapat satu contoh yang dikelompokkan ke dalam bentuk interferensi leksikal, yaitu kata 'workshop'. Kata tersebut telah memiliki padanan kata dalam bahasa 
Indonesia, yakni 'gelar wicara'. Masuknya unsur bahasa asing ke dalam bahasa Indonesia sering kali menimbulkan kesalahan pada kaidah berbahasa dalam bahasa Indonesia.

Berkenaan dengan itu, telah diatur undang-undang mengenai bahasa dalam UU Republik Indonesia no. 24 tahun 2009 tentang Bendera, Bahasa, dan Lambang Negara serta Lagu Kebangsaan. Pada bab III tentang Bahasa Negara bagian kesatu umum dalam pasal 25 ayat (3) yang berbunyi, "Bahasa Indonesia sebagai bahasa resmi negara sebagaimana dimaksud pada ayat (1) berfungsi sebagai bahasa resmi kenegaraan, pengantar pendidikan, komunikasi tingkat nasional, pengembangan kebudayaan nasional, transaksi dan dokumentasi niaga, serta sarana pengembangan dan pemanfaatan ilmu pengetahuan, teknologi, seni, dan bahasa media massa". Meski belum ada peraturan secara resmi tentang penggunaan bahasa di media sosial, namun ada baiknya jika lembaga pemerintah secara berkala turut membantu melestarikan bahasa Indonesia dalam penggunaannya di media sosial.

Penelitian mengenai kata pinjaman dan serapan telah banyak dikaji oleh penelitipeneliti sebelumnya oleh Cholsy (2016), Rahmawati dkk (2016), Fauzi (2014), dan Nurweni (2013). Dalam tulisannya, mereka mengkaji dalam fokus yang serupa, yaitu mengenai fenomena kata pinjaman. Hal yang berbeda dari keempat penelitian tersebut ialah terdapat perbedaan hasil temuan yang signifikan, seperti yang dinyatakan oleh Cholsy (2016) bahwa meski penggunaannya belum terlalu luas, namun mereka yang menggunakan kosakata bahasa Prancis dengan sengaja dalam kesehariannya tidak menganggap hal tersebut mengganggu proses komunikasi, melainkan menganggapnya sebagai sebuah distingsi dengan kelompok atau golongan masyarakat tertentu. sementara itu, Rahmawati dkk (2016) membuktikan bahwa pengaruh bahasa Inggris terhitung cukup signifikan terhadap penggunaan bahasa sehari-hari, sehingga menimbulkan terjadinya fenomena Indoglish khususnya dalam ranah pendidikan oleh kalangan mahasiswa dari berbagai latar belakang. Selanjutnya, menurut hasil penelitian Fauzi (2014), ia menyimpulkan bahwa kata benda lebih banyak diserap dibandingkan dengan kelas kata lainnya, seperti kata kerja, kata sifat, dan kata keterangan. Berbeda dengan peneliti lainnya, Nurweni (2013) menyatakan bahwa makna kata pinjaman dalam data-datanya tidak mengalami perubahan. Sebagai tambahan, ia menyimpulkan bahwa KBBI 2008 perlu mengadakan pembaruan terkait makna kata pinjaman seiring berkembangnya zaman.

Selain beberapa penelitian mengenai kata pinjaman dan serapan tersebut, penelitian mengenai interferensi pernah disusun oleh Mustofa (2018), Purbandini (2017), Jannah (2016), Fauziati (2016), Hidayat dan Setiawan (2015), dan Sukoyo (2011). Pada hasil penelitiannya, Mustofa (2018) menemukan bahwa terdapat beragam interferensi yang ditemukan, yaitu semantis, sintaksis, morfologi, leksikologi, dan fonologi. Sementara, faktor pendorong adanya interferensi ialah dominasi bahasa Indonesia, kurangnya kosakata bahasa Arab, kebiasaan berbahasa. Sementara itu, Purbandini (2017) mengelompokkan data temuannya ke dalam interferensi fonologis, morfologis, dan sintaksis. Setelah itu, ia mengidentifikasi dengan lebih rinci, di antaranya kosakata serapan, istilah bahasa Inggris, serapan salah, dan lain sebagainya. Hasilnya, interferensi morfologis yang paling banyak muncul. Selanjutnya, salah satu simpulan yang ditarik oleh Jannah (2016) berdasarkan hasil yang ditemukan ialah bahwa faktor yang mempengaruhi terjadinya interferensi adalah kebahasaan dan non kebahasaan (sikap bahasa, motivasi 
psikologi, lingkungan, dsb). Penelitian selanjutnya dilakukan oleh Fauziati (2016) yang menemukan bahwa interferensi gramatikal ditemukan pada penggunaan preposisi, konjungsi, bentuk pasif, dan lain-lain. Serta, kedwibahasaan penulis buku dianggap sebagai salah satu faktor ditemukannya interferensi pada LKS Bahasa Inggris tersebut. Dalam penelitiannya lainnya, Hidayat dan Setiawan (2015) mengidentifikasi interferensi dari segi fonologis, morfologis, leksikal, sintaksis, dan faktor penyebab terjadinya. Simpulan yang ditemukan yakni interferensi terjadi karena faktor linguistik dan non linguistik. Sebagai tambahan, Sukoyo (2011) melakukan penelitian mengenai interferensi pada tataran fonologi, morfologi, leksikal, dan sintaksis serta latar belakang terjadinya interferensi dalam acara berita di TV. Ia menemukan bahwa faktor terjadinya interferensi ialah kedwibahasaan penutur, berkurangnya kesetiaan akan penggunaan bahasa Jawa, kurangnya kosakata bahasa Jawa, serta keterbatasan berbahasa Jawa oleh penutur.

Berkaitan dengan penjelasan tersebut, terdapat persamaan dalam penelitian ini yaitu pada subjek penelitiannya, yakni kata pinjaman dan interferensi. Perbedaannya ialah objek penelitian ini fokus kepada kata pinjaman dan interferensi yang ditemukan di media sosial. Maka dari itu, peneliti merumuskan suatu masalah penelitian yaitu apa saja bentuk kosakata bahasa Inggris yang ditemukan dalam takarir pada akun media sosial Instagram Lembaga Pemerintah Indonesia.

\section{TEORI DAN METODOLOGI}

Pembahasan tentang kontak bahasa menurut Haugen pernah diulas oleh Darquennes (2010). Ia mengemukakan bahwa pergeseran bahasa merupakan proses yang bertahap dan bahwa penggunaan bahasa minoritas dalam ranah resmi maupun privat kehilangan posisi dibandingkan bahasa mayoritas.

Definisi kata pinjaman secara umum merujuk kepada masuknya kata atau istilah asing dari bahasa pemberi (donor language) ke dalam bahasa penerima (recipient language). Haugen (1972), Mesthrie dkk (2001: 243), Myers-Scotton (2006: 209), dan Durkin (2014: 3) mengemukakan pendapat yang senada tentang kata pinjaman, yaitu bahwa kata-kata yang telah dipinjam dari bahasa pemberi sebenarnya tidak sepenuhnya dipinjam, karena tidak ada jaminan bahwa bahasa penerima akan mengembalikannya, melainkan diserap ke dalam bahasa penerima. Haugen (1972: 82-91) dan Algeo (1990: 409-410) mengelompokkan macam-macam kata pinjaman, yakni:

1) 'loanwords' atau 'importation'

Masuknya morfem yang dapat diklasifikasikan ke dalam perubahan fonetis, seperti tanpa perubahan, perubahan sebagian, dan perubahan secara keseluruhan.

2) 'loanblends' atau 'hybrids'

Kata pinjaman yang masuk ke dalam tipe ini sering melibatkan bentuk asing di dalamnya. Seperti misalnya, kata pinjaman yang mengandung imbuhan serapan asing.

3) 'loanshifts' atau 'loan translation' atau 'semantic loan'

Kata pinjaman yang mengandung bentuk leksikal asing dan biasanya mempunyai persamaan semantis antara bentuk baru dan lamanya.

Penggunaan kata bahasa asing tersebut dinilai wajar karena faktor kebutuhan. Namun, jika kata dalam bahasa asing digunakan dalam situasi yang keliru atau tidak seharusnya, hal tersebut dapat menuntun kepada peristiwa kontak bahasa lainnya, yakni 
interferensi. Sementara, interferensi didefinisikan sebagai penggunaan unsur bahasa lain oleh dwibahasawan secara individual dalam suatu bahasa, tetapi ciri-ciri bahasa lain itu masih kentara (Kridalaksana, 2008: 95). Weinreich (1968) pertama kali pada 1953 memperkenalkan istilah interferensi yang merujuk kepada perubahan pada elemenelemen kebahasaan yang terjadi pada penutur dwibahasa karena terjadinya persentuhan bahasa dengan unsur lainnya. Namun, inteferensi dianggap sebagai pengacauan menurut Nababan (1984, dalam Chaer dan Agustina, 2014: 121). Dalam tulisannya, Zima (2007) berpendapat bahwa istilah dan konsep 'pinjaman' mulanya digunakan pada leksikon, namun terbukti dari penelitian-penelitian sejak tahun 1930 yang menunjukkan adanya contoh morfem bahkan fonem pinjaman.

Weinreich (1968) menggolongkan interferensi ke dalam tiga bentuk, yaitu interferensi fon, gramatikal, dan leksikal. Pada tataran interferensi fon, terdapat fonemfonem yang tidak memiliki padanan dalam bahasa penerima. Seperti misalnya, fonem $/ \mathrm{x} /$ pada bahasa Inggris akan mengalami perubahan menjadi /ks/ dalam contoh kata 'maximal' yang berubah menjadi /maksimal/. Pada tataran gramatikal, terdapat tipe-tipe tertentu seperti penggunaan morfem bahasa A dalam tuturan maupun tulisan pada bahasa $B$, penerapan hubungan gramatika bahasa A ke morfem B dalam tuturan bahasa $B$, dan identifikasi spesifik dari morfem B dengan morfem A, serta perubahan fungsi dalam morfem B pada gramatika bahasa A (Weinreich, 1968: 30). Pada tataran leksikal, tipe ini mencakup penambahan penggunaan kata asli dari bahasa yang terkena dampak dalam proses penyesuaian dengan bahasa asing.

Dalam penelitian ini, peneliti menggunakan sumber data berupa akun resmi Instagram lembaga pemerintah di Indonesia, yaitu @bekrafid, @infobmkg, @ristekdikti, @kemenpar, @kemdikbud.ri, @kemenkominfo, @kemenhub151, dan @kemlu_ri. Data yang digunakan berupa kosakata pinjaman dan interferensi yang ditemukan dalam takarir pada akun media sosial tersebut. Berkaitan dengan adanya perubahan struktur lembaga pemerintahan pada Oktober 2019, terdapat pula perubahan pada Kementerian Riset dan Teknologi (Kemenristekdikti) menjadi Kementerian Riset dan Teknologi/Badan Riset dan Inovasi Nasional (Kemenristek/BRIN). Oleh karena itu, terdapat perubahan pula pada akun media sosialnya yang berubah dari @ristekdikti menjadi @kementerianristekbrin. Selain itu, terjadi penggabungan Kementerian Pariwisata (Kemenpar) dan Badan Ekonomi Kreatif (Bekraf) menjadi Kementerian Pariwisata dan Ekonomi Kreatif/Badan Pariwisata dan Ekonomi Kreatif (Kemenparekraf) yang berimbas pada berubahnya akun media sosial kedua lembaga pemerintah tersebut, yang semula @kemenpar dan @bekrafid lalu digabung menjadi @kemen.parekraf.

Dalam menyediakan data, peneliti menerapkan metode pengamatan dengan teknik tangkapan layar. Peneliti melakukan pembatasan pengambilan data, yakni hanya pada rentang tanggal 10 hingga 24 Agustus 2019 saja dengan pertimbangan banyaknya agenda kenegaraan yang dilaksanakan oleh tiap-tiap lembaga pemerintah tersebut.

Peneliti lalu mengelompokkan hasil temuan kosakata pinjaman ke dalam bentukbentuknya sesuai teori dari Haugen (1972) dan interferensi berdasarkan teori dari Weinreich (1968). Namun, peneliti melakukan penyesuaian pada bentuk-bentuk interferensi dengan menggunakan istilah yang lebih banyak digunakan. Dalam menyajikan hasil analisis data, peneliti memaparkannya ke dalam tabel dengan menyertai deskripsi analisis data tersebut. Pada bagian analisis data, peneliti juga menggunakan acuan dari 
Kamus Besar Bahasa Indonesia daring (KBBI Daring, 2016) yang diakses melalui gawai pribadi.

\section{HASIL DAN PEMBAHASAN}

Sebagaimana permasalahan mengenai kosakata pinjaman dan interferensi bahasa Inggris yang telah dijabarkan pada bagian sebelumnya, peneliti memaparkan hasil analisis data yang ditemukan dalam takarir pada media sosial Instagram Lembaga Pemerintah Indonesia, yang meliputi bentuk kata pinjaman berupa loanwords, loanblends, dan loanshifts serta interferensi pada tataran fonologis, morfologis, dan leksikal.

\section{Bentuk Kosakata Pinjaman Bahasa Inggris}

Menurut Haugen (1972), kata pinjaman dikelompokkan ke dalam tiga bentuk, yaitu loanwords, loanblends, dan loanshifts. Bentuk loanwords bisa berupa perubahan secara pelafalan (fonologis) atau ejaan (ortografis). Sementara, bentuk loanblends bisa berupa kata pinjaman yang diikuti dengan afiks. Selanjutnya, bentuk loanshifts mengandung persamaan semantik pada unsur serapannya.

\section{'Loanwords'}

Berikut adalah tabel yang menunjukkan hasil temuan bentuk loanwords:

Tabel 1. Sampel Kosakata Pinjaman Bentuk Loanwords

\begin{tabular}{ccc}
\hline No. & Kata pinjaman & Kata bahasa inggris \\
\hline 1. & adrenalin & adrenaline \\
2. & akademik & academic \\
3. & diskon & discount \\
4. & efisiensiency \\
5. & familier & familiar \\
6. & format & format \\
7. & ide & idea \\
8. & infografik & infographic \\
9. & kolom & column \\
10. & komentar & comment \\
11. & komuter & commuter \\
12. & konsisten & consistent \\
13. & koordinat & coordinate \\
14. & normal & normal \\
15. & profil & profile \\
16. & program & program \\
17. & robot & robot \\
18. & teknologi & technology \\
\hline
\end{tabular}

Berdasarkan tabel di atas, dapat dilihat bahwa sebagian besar bentuk loanwords mengalami perubahan secara pelafalan maupun ejaan. 


\section{Perubahan lafal}

Dalam kategori ini, terdapat beberapa contoh bentuk kata loanwords yang mengalami perubahan dalam pengucapannya, seperti 'format', 'normal', 'program', dan 'robot' diucapkan berbeda dalam kedua bahasa tersebut. Meski memiliki ejaan yang sama persis dengan kata asalnya, namun kata-kata pinjaman tersebut berbeda dalam pengucapannya karena telah diserap ke dalam bahasa Indonesia.

\section{Perubahan ejaan}

Dalam kategori perubahan ini terdapat beberapa contoh yang ditemukan dengan mengganti huruf ' $c$ ' menjadi ' $k$ ' seperti dalam contoh 'akademik' dari 'academic', 'diskon' dari 'discount', 'infografik' dari 'infographic', 'kolom' dari 'column', 'komentar' dari 'comment', 'komuter' dari 'commuter', 'konsisten' dari 'consistent', 'koordinat' dari 'coordinate', dan 'teknologi' dari 'technology'.

\section{Pelesapan huruf akhir}

Dalam kategori ini, terdapat beberapa contoh, misalnya pada kata 'adrenalin' yang berasal dari kata 'adrenaline'. Penulisan yang berubah terletak pada penghilangan huruf akhir 'e' yang juga terjadi pada kata 'koordinat' dari 'coordinate', dan 'profil' dari 'profile'. Dalam kasus serupa juga terjadi penghilangan huruf akhir ' $\mathrm{t}$ ' terjadi pada kata 'diskon' dari 'discount', 'komentar/komen' dari 'comment', dan 'konsisten' dari 'consistent'. Dalam kategori pelesapan huruf akhir ini, secara otomatis terdapat perubahan pengucapan dalam kata pinjamannya.

\section{Perubahan huruf vokal}

Sebagai tambahan, ditemukan juga bentuk pelesapan vokal akhir pada contoh kata 'ide' dari 'idea' serta penggantian huruf vokal pada 'familier' dari 'familiar'.

\section{'Loanblends'}

Berikut adalah tabel yang menunjukkan hasil temuan bentuk loanblends:

Tabel 2. Sampel Kosakata Pinjaman Bentuk Loanblends

\begin{tabular}{ccc}
\hline No. & Kata pinjaman & Kata bahasa Inggris \\
\hline 1. & dikoordinir & coordinated \\
2. & dipresentasikan & presented \\
3. & memposisikan & to position \\
4. & mengakomodir & to accommodate \\
5. & mengapresiasi & to appreciate \\
6. & berdomisili & domiciled \\
7. & berpartisipasi & participate \\
8. & terdiferensiasi & differentiated \\
9. & terverifikasi & verified \\
10. & pemograman & programming \\
11. & pengaplikasiannya & application \\
12. & kestabilan & stability \\
\hline
\end{tabular}


Berdasarkan tabel di atas, dapat dilihat bahwa bentuk loanblends mengalami penambahan afiks pada kata pinjamannya.

\section{Prefiks di-}

Dalam kategori ini, terdapat contoh yang ditemukan, seperti pada kata 'dikoordinir'. Kata pinjaman 'koordinir' berasal dari kata bahasa Inggris 'coordinate' dan merupakan bentuk tidak baku dari 'koordinasi' yang memiliki arti mengatur. Kata tersebut mengalami penambahan prefiks di- sehingga menjadi 'dikoordinir' yang berarti 'diatur'.

\section{Prefiks meN-}

Dalam kategori ini, terdapat contoh yang ditemukan, yaitu kata 'mengakomodir' dan 'mengapresiasi'. Kata pinjaman 'akomodir' berasal dari kata bahasa Inggris 'accommodate' dan merupakan turunan dari kata 'akomodasi' yang mendapat awalan meN- dan memiliki arti 'sesuatu yang disediakan', sehingga kata 'mengakomodir' memiliki arti 'menyediakan'. Kata pinjaman 'mengapresiasi' terdiri dari kata 'apresiasi' yang berasal dari 'appreciate' dan mendapat awalan meN- dan memiliki arti kata 'menghargai'.

\section{Prefiks ber-}

Dalam kategori ini, terdapat contoh yaitu 'berdomisili' yang terdiri dari kata pinjaman 'domisili' dan mendapat awalan ber- dan memiliki arti 'bertempat tinggal' atau 'berkediaman'.

\section{Prefiks ter-}

Dalam kategori ini, terdapat contoh pada kata 'terdiferensiasi' dan 'terverifikasi'. Kata pinjaman 'diferensiasi' yang berarti 'proses pembedaan' mendapatkan awalan tersehingga memiliki arti 'terbedakan'. Selanjutnya, kata 'verifikasi' yang berarti 'pemeriksaan' mendapatkan awalan ter- sehingga memiliki arti 'terperiksa' atau 'telah mengalami proses pemeriksaan'.

\section{Konfiks peN- dan -kan}

Dalam kategori ini, terdapat contoh pada kata 'pengaplikasiannya'. Kata 'pengaplikasian' terdiri dari kata pinjaman 'aplikasi' yang berarti penerapan. Kata tersebut mendapatkan awalan peN- dan akhiran -kan serta klitik -nya sehingga memiliki arti 'proses penerapan'.

\section{Konfiks me- dan -kan}

Dalam kategori ini, contoh yang ditemukan ialah kata 'memposisikan'. Kata 'memposisikan' merupakan kata tidak baku dari 'memosisikan' yang terdiri dari kata 
pinjaman 'posisi' dan mendapat awalan me- dan akhiran -kan, sehingga berarti sama dengan kata 'meletakkan'.

\section{Konfiks peN- dan -an}

Dalam kategori ini, terdapat contoh pada kata 'pemograman. Kata tersebut merupakan kata tidak baku dari 'pemrograman' yang terdiri dari kata pinjaman 'program' dan mendapatkan awalan peN- dan akhiran -an yang memiliki arti 'proses memprogram'.

\section{Konfiks ke- dan -an}

Dalam kategori ini, contoh yang ditemukan yaitu kata 'kestabilan'. Kata tersebut terdiri dari kata pinjaman 'stabil' dan disertai awalan ke- dan akhiran -an. 'stabil' memiliki arti 'mantap' atau 'tetap', sehingga arti kata tersebut menjadi 'ketetapan'.

\section{'Loanshifts'}

Berikut adalah tabel yang menunjukkan hasil temuan bentuk loanshifts:

Tabel 3. Sampel Kosakata Pinjaman Bentuk Loanshifts

\begin{tabular}{ccc}
\hline No. & Kata pinjaman & Kata bahasa Inggris \\
\hline 1. & audio visual & audio visual \\
2. & desain interior & interior design \\
3 & konferensi pers & press conference \\
4. & sesi panel & panel session \\
5. & super prioritas & priority super \\
6. & teknologi digital & digital technology \\
\hline
\end{tabular}

Berdasarkan tabel tersebut, dapat dilihat bahwa terdapat beberapa contoh loanshifts yang ditemukan dalam bentuk frasa yang memiliki kemiripan makna dengan bahasa pemberi. Seperti contoh, pada kata bahasa Inggris 'audio visual' yang memiliki bentuk sama dengan kata pinjamannya, yang mengandung arti audio-visuil. Pada contoh selanjutnya, kata pinjaman 'desain interior' memiliki makna semantis yang sama dengan 'interior design'. Kata 'interior' memiliki arti bagian dalam, sedangkan 'design' memiliki arti rancangan, dan jika digabung berarti 'rancangan bagian dalam' yang artinya sama dengan 'desain interior'.

Contoh serupa juga terjadi pada kata majemuk 'konferensi pers' yang diterjemahkan dari 'press conference', 'sesi panel' yang dipinjam dari kata asalnya yakni 'panel session', 'super prioritas' dari 'priority super', serta 'teknologi digital' dari 'digital technology'. Contoh-contoh tersebut memiliki arti semantis yang serupa dengan kata asalnya serta mengalami perubahan pada strukturnya, yakni diterangkan-menerangkan dari bentuk asalnya berupa menerangkan-diterangkan. Selain itu, contoh-contoh tersebut mengalami perubahan pada segi pelafalan dan ejaan seperti pada bentuk kata pinjaman pada umumnya, salah satunya ialah perubahan sufiks. 


\section{Bentuk Interferensi Bahasa Inggris}

Weinreich (1968) berpendapat bahwa interferensi mengacu pada sistem kebahasaan yang berubah karena mengalami kontak bahasa yang dialami oleh penutur dwibahasa. Interferensi yang dibahas dalam penelitian ini dikelompokkan ke dalam tataran fonologis, morfologis, dan leksikal.

\section{'Interferensi Fonologis'}

Berikut adalah tabel yang menunjukkan hasil temuan data interferensi fonologis:

Tabel 4. Sampel Interferensi Fonologis

\begin{tabular}{ccc}
\hline No. & Interferensi & Kata bahasa Inggris \\
\hline 1. & gaes & guys \\
2. & hoaks & hoax \\
3. & studi & study \\
4. & templat & template \\
\hline
\end{tabular}

Berdasarkan tabel tersebut, dapat dilihat bahwa contoh interferensi fonologis mengalami perubahan bunyi dari kata asalnya. Seperti contoh pada kata 'gaes' yang berasal dari kata bahasa Inggris 'guys' yang berarti 'teman-teman'. Pada kata tersebut, terdapat perubahan bunyi yang semula /g^Iz/ lalu disesuaikan dengan pengucapan bahasa Indonesia. Pada kata 'hoaks' yang berarti 'berita bohong' berasal dari kata 'hoax' mengalami perubahan bunyi, yaitu semula dilafalkan dengan /hōks/ menjadi /hoaks/. Contoh lainnya, pada kata 'studi' memiliki arti 'penelitian' yang berasal dari kata 'study' mengalami perubahan bunyi yang semula dilafalkan /stədē/ menjadi /studi/. Selanjutnya, kata 'templat' yang berarti 'format' berasal dari 'template' yang semula dilafalkan dengan bunyi /templət/ menjadi /templat/.

\section{'Interferensi Morfologis'}

Berikut adalah tabel yang menunjukkan hasil temuan data interferensi morfologis:

Tabel 5. Sampel Interferensi Morfologis

\begin{tabular}{ccc}
\hline No. & Interferensi & Kata bahasa Inggris \\
\hline 1. & amunisi & ammunition \\
2. & destinasi & destination \\
3. & diplomasi & diplomacy \\
4. & diskusi & discussion \\
5. & intensitas & intensity \\
6. & kapasitas & capacity \\
7. & klasifikasi & classification \\
8. & komitmen & commitment \\
9. & kreator & creator \\
10. & optimisme & optimism \\
11. & prediksi & prediction \\
12. & registrasi & registration \\
13. & simulasi & simulation \\
14. & sosialisasi & socialization \\
\hline
\end{tabular}


Berdasarkan tabel tersebut, dapat dilihat bahwa bentuk interferensi morfologis yang mengalami perubahan pada imbuhan akhir/akhiran (sufiks).

\section{Sufiks '-asi'/'-si' dari '-ation'/'-tion' /'-sion'}

Seperti contoh pada kata 'amunisi' yang berasal dari kata bahasa Inggris 'ammunition' mengalami perubahan sufiks '-ation' dan '-sion' menjadi '-asi' dan 'si'. Hal serupa juga berlaku pada perubahan sufiks '-asi' dari '-contoh kata 'destinasi' dari kata 'destination', 'klasifikasi' dari kata 'classification', 'prediksi' dari kata 'prediction', 'registrasi' dari kata 'registration', 'simulasi' dari kata 'simulation', serta 'diskusi' dari kata 'discussion'. Selanjutnya, perubahan juga terjadi pada sufiks '-isasi' yang berasal dari 'itation'/'-ization' pada contoh 'sosialiasi' dari 'socialization'. Beberapa bentuk asli dari kata-kata tersebut berasal dari bahasa Belanda. Seperti kata 'amunisi' yang berasal dari 'ammunitie', begitu juga 'destinatie', dan lain-lain. Akan tetapi, kemudian kata-kata pinjaman tersebut mengalami proses pembenaran sebagai pola yang menyebabkan semua kosakata berakhiran serupa tersebut dalam bahasa Inggris menjadi -asi/-si jika disesuaikan ke dalam bahasa Indonesia. Hal tersebut terjadi karena dewasa ini kontak dengan bahasa Inggris jauh lebih intensif dan dominan dibandingkan dengan bahasa Belanda.

\section{Sufiks '-si' dari '-cy'}

Perubahan sufiks lainnya yaitu ditemukan pada contoh kata 'diplomasi' yang berasal dari kata 'diplomacy' yang mengalami perubahan '-si' dari '-cy'. Serupa dengan penjelasan di bagian sebelumnya, terdapat beberapa kata yang aslinya berasal dari bahasa Belanda, dalam kategori ini ialah 'diplomatie' yang selanjutnya menyebabkan kata berakhiran '-tie' dalam bahasa Inggris menjadi '-cy'.

\section{Sufiks '-itas' dari '-ity'}

Pada kategori ini, terdapat juga perubahan sufiks '-itas' dari '-ity' pada contoh kata 'kapasitas' yang berasal dari kata 'capacity' dan 'intensitas' yang berasal dari kata 'intensity'. Pada kategori ini, terdapat pula kata asli yang berasal dari bahasa Belanda seperti 'capaciteit' dan 'intensiteit'. Kata berakhiran '-iteit' tersebut selanjutnya mengalami proses pembenaran yang dalam bahasa Inggris menjadi '-ity' lalu disesuaikan lagi menjadi '-itas' ke dalam bahasa Indonesia.

\section{Sufiks '-men' dari '-ment'}

Sufiks lain yang ditemukan pada penelitian ini ialah '-ment' yang berubah menjadi 'men' pada contoh kata 'commitment' yang berubah menjadi 'komitmen'. 


\section{Sufiks '-or' dari '-or'}

Selanjutnya, sufiks '-or' juga merupakan sufiks kata serapan yang ditemukan pada contoh kata 'kreator' yang berasal dari kata 'creator'.

\section{Sufiks '-isme' dari '-ism'}

Pada kategori ini, sufiks '-ism' mengalami perubahan menjadi '-isme' dalam bahasa Indonesia yang ditemukan pada contoh kata 'optimism' yang berubah menjadi 'optimisme'.

\section{'Interferensi Leksikal'}

Berikut adalah tabel yang menunjukkan hasil temuan data interferensi leksikal:

Tabel 6. Sampel Interferensi Leksikal

\begin{tabular}{|c|c|c|}
\hline No. & Interferensi & Padanan kata/arti \\
\hline 1. & benefit & manfaat \\
\hline 2. & brand image & penjenamaan \\
\hline 3. & caption & takarir \\
\hline 4. & deadline & tenggat \\
\hline 5. & direct flight & penerbangan langsung \\
\hline 6. & door prize & hadiah \\
\hline 7. & download & unduh \\
\hline 8. & $e$-mail & surel; surat elektronik \\
\hline 9. & flashback & kilas balik \\
\hline 10. & followers & pengikut \\
\hline 11. & halal tourism & wisata halal \\
\hline 12. & hashtag & tagar; tanda pagar \\
\hline 13. & highlight & sorotan \\
\hline 14. & instagrammable & terinstagramkan; layak instagram \\
\hline 15. & jogging track & lintasan joging \\
\hline 16. & life jacket & jaket pelampung \\
\hline 17. & live streaming & aliran langsung \\
\hline 18. & mention & sebutan; menyebut \\
\hline 19. & on the spot & di tempat \\
\hline 20. & postingan & kiriman \\
\hline 21. & potential buyer & pembeli potensial \\
\hline 22. & slide & salindia \\
\hline 23. & $\operatorname{tag}$ & tandai \\
\hline 24. & talkshow & gelar wicara \\
\hline 25. & workshop & lokakarya \\
\hline
\end{tabular}

Berdasarkan tabel di atas, dapat dilihat bahwa bentuk interferensi leksikal muncul meski telah ada padanan katanya dalam bahasa Indonesia.

\section{Padanan}

Dalam kategori ini, terdapat beberapa contoh yang telah memiliki padanan kata bahasa Indonesia yang telah dimasukkan ke dalam KBBI. Seperti contoh, brand image, caption, deadline, download, email, flashback, hashtag, slide, talkshow, dan workshop. Kata 'brand image' memiliki padanan kata yaitu 'penjenamaan'. Kata 'caption' memiliki padanan 
kata yaitu 'takarir'. Dalam KBBI, takarir didefinisikan sebagai keterangan yang biasanya terdiri atas satu atau beberapa kalimat yang menjelaskan isi dan maksud gambar. Kata 'deadline' memiliki padanan kata 'tenggat' yang berarti batas waktu.

Selanjutnya, kata 'download' memiliki padanan kata 'unduh' yang berarti mengopi berkas dari layanan informasi daring atau dari komputer. Kata 'email' memiliki padanan kata 'surel' atau surat elektronik. Kata 'flashback' memiliki padanan kata 'kilas balik' yang artinya pandangan kembali atas kejadian sebelumnya. Kata 'hashtag' memiliki padanan kata 'tagar' atau 'tanda pagar' yang didefinisikan sebagai tanda untuk merujuk pada topik sebuah kiriman status dalam media jejaring sosial. Kata 'slide' memiliki padanan kata 'salindia' yang didefinisikan sebagai terawang fotografi pada pelat kaca tipis yang diatur agar dapat diproyeksikan. Selanjutnya, kata 'talkshow' memiliki padanan kata 'gelar wicara' yang diartikan sebagai acara bincang-bincang di televisi atau radio yang dilakukan dalam suatu panel yang terdiri dari atas beberapa tokoh dan dipandu oleh pembawa acara. Selain itu, kata 'workshop' memiliki padanan kata 'lokakarya' yang dideskripsikan sebagai pertemuan antara para ahli untuk membahas masalah praktis atau yang bersangkutan dengan pelaksanakan dalam bidang keahliannya.

\section{Arti kata atau terjemahan}

Dalam kategori ini, terdapat beberapa contoh kata yang belum memiliki padanan kata resmi dalam KBBI. Seperti contoh, kata direct flight, door prize, followers, halal tourism, highlight, instagrammable, jogging track, life jacket, live streaming, mention, on the spot, postingan, potential buyer, dan tag. Pada contoh tersebut, masing-masing secara berurutan memiliki arti sebagai berikut, yaitu penerbangan langsung, hadiah, pengikut, wisata halal, sorotan, terinstagramkan atau layak Instagram, lintasan jogging, jaket pelampung, aliran langsung, sebutan atau menyebut, di tempat, kiriman, pembeli potensial, dan tandai.

\section{Simpulan}

Berdasarkan analisis dan pembahasan pada bagian sebelumnya, peneliti menarik kesimpulan sebagai berikut:

1) Kata pinjaman yang ditemukan dalam penelitian ini berupa bentuk loanwords, loanblends, dan loanshifts. Kata pinjaman bentuk loanwords yang ditemukan mengalami perubahan lafal dan ejaan. Perubahan ejaan yang dialami dapat berupa perubahan huruf, pelesapan huruf akhir, dan perubahan huruf vokal. Kata pinjaman bentuk loanblends yang ditemukan mengalami perubahan pada afiks. Afiks yang ditemukan pada penelitian ini berupa prefiks di-, meN-, ber-, dan ter- serta konfiks peN- dan -kan, meN- dan -kan, peNdan -an, serta ke- dan -an. Selanjutnya, bentuk loanshifts yang ditemukan merujuk kepada kata yang memiliki arti semantis yang serupa.

2) Interferensi yang ditemukan dalam penelitian ini berupa bentuk fonologis, morfologis, dan leksikal. Data interferensi fonologis mengalami perubahan pada bunyi semula. Sementara, data interferensi morfologis mengalami perubahan pada sufiks kata serapan, seperti -asi, -si, -itas, -men, -or, dan -isme. Selanjutnya, interferensi leksikal yang ditemukan pada penelitian ini ada yang telah memiliki padanan kata dengan makna serupa dalam KBBI, dan ada yang hanya memiliki terjemahan saja.

Sehubungan dengan kesimpulan yang ditarik dari penelitian ini, maka peneliti menyarankan agar admin akun media sosial Instagram lembaga terkait lebih 
memperhatikan tata bahasa dan pilihan kata bahasa Indonesia yang digunakan, serta penggunaan bentuk bakunya. Selain itu, peneliti juga menyarankan agar peneliti selanjutnya yang tertarik untuk mengkaji subjek yang serupa dapat lebih mengeksplorasi objek penelitiannya. Sebagai tambahan, saran selanjutnya ditujukan kepada lembaga yang berwenang, yaitu Badan Pengembangan Bahasa dan Perbukuan agar senantiasa memperbarui padanan kata bahasa Indonesia yang semakin banyak terpapar kata atau istilah bahasa asing agar dapat memenuhi kebutuhan kosakata bahasa Indonesia seiring perkembangan zaman.

\section{DAFTAR PUSTAKA}

Algeo, J. (1990). Borrowing. Dalam Polomé, E. C. (Ed.), Research Guide on language change. (hal. 409-413). New York: Mouton de Gruyter.

Chaer, A., dan Agustina, L. (2014). Sosiolinguistik: perkenalan awal. Jakarta: Rineka Cipta.

Cholsy, H. (2016). Kata serapan bahasa Perancis sebagai sebuah distingsi dalam ranah kuliner dan mode di Indonesia. Proceeding International Seminar Prasasti III. Surakarta: 2-3 Agustus 2016. Hal. 362-367.

Darquennes, J. (2010). Language contact and language conflict in autochtonous language minority settings in th EU: A preliminary round-up of guiding principles desiderata. Multilingua 29, November 2010, hal. 337-351.

Durkin, P. (2014). Borrowed words: a history of loanwords in English. Oxford: Oxford University Press.

Fauzi, I. (2014). English borrowings in indonesian newspapers. Journal on English as a Foreign Language. Vol. 4, No. 1, Maret 2014, hal. 15-28.

Fauziati, E. (2016). Interferensi gramatikal bahasa Indonesia dalam Bahasa Inggris: kasus pada buku lks bahasa Inggris untuk SLTP di Surakarta. Jurnal Penelitian Humaniora. Vol. 17, No. 2, Agustus 2016, hal. 96-109.

Haugen, E. (1972). The Ecology of Language. California: Standford University Press.

Hidayat dan Setiawan, T. (2015). Interferensi Bahasa Jawa ke dalam Bahasa Indonesia pada keterampilan berbicara siswa Negeri 1 Pleret, Bantul. LingTera. Vol. 2, No.2, Oktober 2015, hal. 156-168.

Jannah, L. (2016). Interferensi bahasa Indonesia dalam pemakaian bahasa Inggris pada wacana tulis siswa. EDU-KATA. Vol. 3, No. 1, Februari 2016, hal. 81-86.

KBBI Daring. (2016). Badan Pengembangan Bahasa dan Perbukuan, Kementerian Pendidikan dan Kebudayaan Republik Indonesia. Diakses pada 8 September 2019 dari laman https://kbbi.kemdikbud.go.id/

Kridalaksana, H. (2008). Kamus Linguistik Edisi Keempat. Jakarta: Gramedia Pustaka Utama.

Mesthrie, R., dkk. (2001). Introducing sociolinguistics, 2nd Ed. Edinburgh: Edinburgh University Press.

Mustofa, M. A. (2018). Interferensi Bahasa Indonesia terhadap Bahasa Arab (Analisis Interferensi dalam Pembelajaran Maharah al-Kalam). AN-NABHIGOH. Vol. 20, No. 02, tahun 2018, hal. 139-161. 
Myers-Scotton, C. (2006). Multiple voices: an introduction to bilingualism. UK: Blackwell Publishing. Pdf.

Nurweni, A. (2013). Meaning of English loanwords in indonesian articles of sport. Jurnal HUMANIORA. Vol. 23, No. 2, Juni 2013, hal. 184-195.

Purbandini, W. K. (2017). Interferensi bahasa pada tugas mata kuliah komposisi mahasiswa TK. II Jurusan Bahasa Inggris. Sigma-Mu. Vol. 9, No. 2, September 2017, hal. 44-55.

Rakhmawati, A. dkk. (2016). A phenomenon of indoglish usage at universities in Indonesia: breaking down the motives from sociolinguistics perspectives. Proceeding International Seminar Prasasti III. Surakarta: 2-3 Agustus 2016. Hal. 146-152.

Sukoyo, J. (2011). Interferensi bahasa Indonesia dalam acara berita berbahasa Jawa "Kuthane Dhewe" di TV Borobudur Semarang. Lingua Jurnal Bahasa dan Sastra. Vol. VII, 2 Juli 2011, hal. 95-103.

Thomason, S. G. (2001). Language contact: an introduction. Edinburgh: Edinburgh University Press.

Weinreich, U. (1968). Language in contact findings and problems. Hague: Mouton. Pdf.

Undang-Undang Republik Indonesia nomor 24 tahun 2009. Diakses dari laman www.badanbahasa.kemdikbud.go.id pada 9 September 2019. Pdf.

Zima, P. (2007). Why languages and contacts?. Journal of Language Contact-THEMA 1: hal. 101-115. 